\title{
On certain remarkable points in magnets
}

\section{R. Blondlot}

To cite this article: R. Blondlot (1876) On certain remarkable points in magnets, Philosophical Magazine Series 5, 1:4, 333-335, DOI: 10.1080/14786447608639047

To link to this article: http://dx.doi.org/10.1080/14786447608639047

$$
\text { 曲 Published online: } 13 \text { May } 2009 .
$$

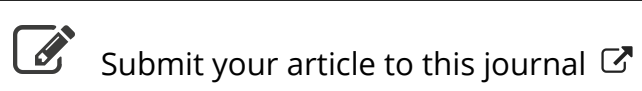

\footnotetext{
Џll Article views: 2
}

Q View related articles $\longleftarrow$ 
monia. I intend to prepare and analyze it further.-Comptes Rendus de l'Académie des Sciences, vol. lxxxii. pp. 223-226.

The lines described by M. Schuster* have not been found again by MM. Stearn and Wüllner, who, after verifying the disappearance of the band spectrum, saw the well-known spectrum appcar of the oxide of carbon or acetylene. Schuster's tubes more carefully prepared gave me, after a certain time, the bright lines of hydrogen only. What, then, was the origin of the lines described in the memoir of 1872 ? It is permissible to attribute them to the vapour of sodium.

In fact, we remark that the published numbers were not got by direct measurement, but refer to the nitrogen lines of Pliicker's spectrum which appear to coincide with the lines observed; and these, moreover, are not the most characteristic. Now, if sodium be heated in a Geissler tube, or in an apparatus like that described in $\$ 1$, and the spark be made to pass, a bright greenish yellow light is produced, the spectrum of which is composed of the following lines :Spectrum of sodium.

$$
\begin{aligned}
& 615 \cdot 5 \text { double . . . . . . . 515.3 } \\
& 589 \cdot 2 \quad, \quad \text { (D) } \ldots \ldots 4498 \cdot 3 \\
& 568.7, \quad \ldots \ldots \ldots 4467
\end{aligned}
$$

These numbers are very near those of M. Schuster; only the line 498.3 does not figure in his Plate, it is replaced by 489.4 . Conversely, we find in that Plate three extreme lines-628.8, $421 \cdot 4$, and $418 \cdot 4$, which $I$ have not been able to produce, nor are they indicated by MM. Thalén and Lecoq de Boisbaudran. A curious thing, these lines nearly coincide with the characteristic lines of rubidium $(629 \cdot 6,421 \cdot 6$, and $420 \cdot 2)$. I would not by any means say that this metal was present in M. Schuster's sodium, especially with the uncertainty of the wave-lengths; but in any case it must very readily give a spectrum in a Geissler tube ; for potassium offers much better facilities for this kind of experiments than sodium. It furnishes, without difficulty, a very pure spectrum, of which the principal lines are the following:-

$\begin{array}{lccc} & \text { Spectrum of potassium. } \\ 583 & 535 \cdot 3 & 511 & 404 \cdot 4 \\ 580 & 533 \cdot 5 & 509 & \\ 575 \cdot 3 & 532 & & \end{array}$

It must be possible, emplnying the same method, but under slightly different conditions of experiment, to produce not only the secondary spectra of the alkali-metals, as we have done in the present researches, but also their primary spectra, for the interesting discovery of which we are indebted to Messrs. Roscoe and Schuster.-Comptes Rendus de l'Académie des Sciences, vol. lxxxii. pp. $274,27 \overline{0}$.

ON CERTAIN REMARKABLE POINTS IN MAGNETS. BY R. BLONDLOT.

If a very short magnetic needle, the centre of gravity of which is supportid, be brought near the surface of a magnet, the direction

* Pogg. Ann. vol. exlvii, p. 106. 
of the needle is seen to vary at the same time as the coordinates of its centre of rotation. Among these directions there are some remarkable ones to which we would call attention-namely, those normal to the surface of the magnet. For the sake of brevity, we will give to the points to which they correspond the name of orthogonal points.

To take an example, let us consiler a magnetized bar having the form of a rectangnlar parallelepiped; on each half of the bar we shall find five orthogonal points:- - one on the terminal face, at the point where the magnetic axis meets it; and one on each of the four lateral faces, situated on the right line joining the centres of the short sides of this face, the last four points being symmetrical, two and two.

Around each of the points we are considering, the directions are such that, reckoning from the surface of the magnet inwards, they are always convergent in any plane drawn through the normal.

A first property of orthogonal points is the following:-

If a small magnetic body be placed on an orthogonal point, more mechanical work will be requisite, in order to remove the small body thence to infinity, than if it had becn placed on any other neighbouring point of the surface of the magnet. In other terms, the orthogonal point presents a maximum of the work above-mentioned.

The demonstration of this theorem is very simple.

With respect to terrestrial magnetism, the orthogonal points of the surface of the earth are what are somewhat improperly called the magnetic poles. Halley and Hansteen believed in the existence of tour of these poles; Gauss and Duperrey admit only two, or, more precisely, two polar regions. Parry, John Ross, James Ross, Dumont d'Urville, and Wilke were able to determine approximately their positions.

On a given line, also, points possessing the same property of maximum of work of removal to infinity are found; they are those for which the magnetic action is normal to the curve.

We will remark that all these maxima presented by orthogonal points might be replaced by minima for surfaces presenting suitable ratios of curvature with the surfaces of equal potential. A simple change of sign of the work of sliding conducts immediately to this result.

A second curious property is the following:--

The positions of spontaneous equilibrium of a small magnetic body with respect to a magnet are precisely the orthogonal points. This proposition flows immediately from the fact that the positions of equilibrium of a point situated on a polished surface are those for which the forces acting on the point produce no tangential componeut.

This is confirmed by the following experiment:-A particle of iron is fixed on a flat cork, which is then put to float upon water. If a magnet be brought quite close to the surface of the water, with its lower face horizontal, the cork will be seen to move until the iron particle which it carries is placed precisely under the orthogonal point. If the magnet be placed in any manner whatever in space, the final situation of the iron will indicate the point of con- 
tact of the surface of equal potential which touches the surface of the water.-Comptes Rendus de l'Academie des Sciences, vol. Ixxxii. pp. 454,455 .

\section{ON THE METALLIC REDUCTIONS PRODUCED IN CAPILLARY SPACES.} BY M. BECQUEREL.

When a cracked tube containing a concentrated metallic solution (of nitrate of copper or chloride of cobalt for example) is dipped into a solution of monosulphide of sodium, if the crack is not sufficiently narrow, diffusion is produced, giving rise to the production of metallic sulphide in the solution of copper or cobalt; this sulphide forms a coat adhering pretty strongly to the glass; and then by degrees a deposit of bright metal is seen to form in the molecular space between the coat of sulphide and the glass, on the side of the metallic solution.

Similar effec is are produced by applying to the crack, outside the tube, a strip of paper covered with a layer of freshly precipitated sulphide, fixing it to the surface by means of a wire wound round it. Cobalt, copper, platinum, \&c. have thus been obtained in the metallic state; the first was attracted by the magnet.

Effects like these might indeed take place in organic nature in the case of rupture of tissues or vessels. Suppose, for example, that a vessel which traverses a muscle is ruptured at any point; blood is immediately diffused into the muscle; and a coagulum is formed, which is in contact on one side with the blood, on the other side with the liquid that moistens the muscle. An electrocapillary action will then take place resembling the foregoing, giving rise to a reducing or oxidizing action, according to the nature of the liquid with which the blood is in contact when it coagulates. The products then formed may cooperate in closing the aperture. I merely indicate the forces which come into play, in the impossibility of knowing what products are formed.

Doubtless similar effects are produced in wounds covered with a plaster coated with a substance of a healing nature.

The communication finishes with a recital of the chemical reactions produced in capillary spaces with the cooperation of a voltaic couple of two liquids, adjunct but forming part of the apparatus. The couple is formed of a cracked tube containing a solution of monosulphide of sodium, in which is immersed a slip of platinum; and it is introduced into a test-tube containing a metallic solution. Thus arranged, the two-liquid couple operates in consequence of the reaction of the two liquids in the fissure; two currents result, travelling in the same direction-one the current in question, the other the electrocapillary current described in my previous memoirs. On the other hand, the platinum wire wound rourd the tube touching the crack being the negative electrode at which the reduction is effected, it follows that the two actions are added together, as can readily be explained; and thus the amount of reduction is doubled.

It is to be remarked that electrocapillary apparatus formed of cracked tubes act only so far as the two liquids, penetrating the 